\title{
Natureza e sociedade, evolução e revolução: a geografia libertária de Elisée Reclus ${ }^{1}$
}

Regina Horta Duarte

UFMG

\section{RESUMO}

A obra do geógrafo Elisée Reclus (18301905) possibilita uma fecunda análise das relações entre as concepções sobre a natureza e a história da sociedade na qual ela se constitui. Evidencia-se uma lógica extremamente original em relação aos paradigmas predominantes no século XIX. Reclus suspeitou dos sistemas de determinação oferecidos pela matemática clássica de sua época, obcecada em traduzir e enquadrar a natureza em equações. Questionou os esquemas filosóficos de causalidade no que diz respeito às possibilidades de criação social. Identificava o momento revolucionário ao surgimento do novo, numa leitura instigante do evolucionismo. Sua obra uniu natureza e sociedade, revolução e filosofia, história e geografia, fazer científico e prática política.

Palavras-chave: Natureza e sociedade; Evolucionismo e anarquismo; História e geografia.

\begin{abstract}
The works of the geographer Elisée Reclus (1830-1905) provide a fruitful analysis of the relationship between the ideas about nature and the history of the society where those works emerge. Focusing on his works, one can realize the parallels between his very original geographical and anarchical ideas, as compared to the predominant paradigms of the 19th Century. Reclus was suspicious of the determinist systems offered by the mathematics of his time. He questioned the causal philosophical explanations of the possibilities of social inventions, in a very instigating interpretation of the Evolutionism. His thought joined nature and society, revolution and philosophy, history and geography, scientific works and political practices.

Keywords: Nature and Society; Evolutionism and Anarchism; History and Geography.
\end{abstract}


A erupção vulcânica do Etna, na Sicília, iniciada em fins de janeiro de 1865 , despertou imenso terror entre os habitantes das suas proximidades, lançados à recitação de preces fervorosas e à invocação de santos protetores. $\mathrm{O}$ geógrafo francês Elisée Reclus (1830-1905) notou que, naquele evento trágico - como tudo no mundo - "o infortúnio de alguns trouxe a satisfação de outros". Ao largo do desespero dos montanheses, centenas de curiosos chegavam diariamente para contemplar, de algum ponto seguro, o esplendoroso espetáculo, sobretudo à noite. Mas se a explosão fora inesperada para muitos, uma série de sinais anteriores já despertara o alerta dos cientistas, como as movimentações convulsivas do solo em 1863, assim como algumas mudanças observáveis "no cone supremo do vulcão".

Apesar da ressonância do evento entre seus contemporâneos, para Reclus aquele não passava de um "episódio insignificante na história da montanha", "uma simples pulsação do Etna". ${ }^{3}$ A imagem de pulsação alude a duas outras concepções de Reclus sobre a Terra. Em primeiro lugar, há uma clara referência à idéia de tempo, já que o pulsar é uma atividade constituída no devir, podendo assumir ritmos diversos, em diferentes situações. Tal ênfase afinava-se à visão do autor que inter-relacionava história e geografia, afirmando que "a Geografia não é outra coisa que a História no Espaço, assim como a História é a Geografia no Tempo”, na proposta da realização de uma geografia social. Somado a isso, o pulsar caracteriza o que é vivo, com tudo o que a condição da vida implica, como a criação, a transformação e a morte. Os vulcões assumiam, assim, um significado especial no pensamento de Reclus, como demonstração clara da vida do planeta.

Criticando as concepções correntes nas quais a Terra aparecia como um verdadeiro símbolo da imutabilidade e inércia, Reclus enfatizava a necessidade de considerá-la sob outro ponto de vista, no qual emergia um universo constituído por vibrações mínimas em uma oscilação incessante, mas também por momentos de instabilidade abrupta, quando certos eventos - como erupções e terremotos - expressam, não obstante seu caráter localizado, as transformações mais amplas em curso. Se o homem, durante tanto tempo, considerou o solo sob seus pés como firme e inativo, eis que o saber científico evidenciava "que ele se anima e se agita", integrando uma realidade na qual "tudo se transforma, tudo é móvel no universo, pois o movimento é a condição mesma da vida”. ${ }^{4}$

Mas seria um engano acreditar que tais afirmações integrariam uma visão holística do mundo. Reclus não atribuía à Terra o estatuto de uma entidade quase sagrada, orgânica e substancial, nem detinha uma visão totaliza- 
dora na qual se igualariam homens e rochas, o inerte e o vivo, tudo e todos afinados em um acorde uníssono. ${ }^{5}$ No pensamento desse geógrafo, o mundo físico é vivo não por ser ele próprio um organismo cujo estatuto seria o mesmo dos homens e de outros entes, mas pelo que ele faz viver e dele difere.

Assim, ao descrever a violenta erupção do Etna de janeiro de 1865 e interpretá-la como uma vigorosa pulsação, Reclus alerta para o fato de que aquela montanha não era apenas um vulcão, mas urgia observar toda a região geográfica onde se localizava, realizando um percurso em que as diversas paisagens a norte, sul, leste e oeste da sua cratera ofereciam "uma extraordinária variedade de aspectos, e cada detalhe reforçava a idéia construída sobre a beleza grandiosa do conjunto". A visão mais detida do Etna evidenciava a multiplicidade não apenas de suas formas e paisagens, mas também a das várias formas de vida que ali vicejavam.

Anos depois, Reclus afirmaria que o estudo in loco de qualquer montanha fazia cair por terra todas as imagens de uniformidade estampadas nos mapas escolares, nos quais cumes arredondados e bases regulares figuravam uma homogeneidade tão perfeita como irreal. Tais montanhas simplesmente não existiam. Mapas assim poderiam satisfazer apenas ao espírito tacanho de um século dominado por engenheiros e soldados, "para os quais tudo deve ser traçado linear e regularmente. Alinhamento! Tal é a palavra de ordem desses pobres de espírito que vêem a beleza apenas na simetria, e a vida apenas na rigidez da morte". As montanhas desmentiam, desafiadoramente, o pressuposto de tal simetria, evidenciando mais uma vez a relevância de seu estudo em novas bases, num conhecimento renovador tal como "o ar que se respira".

Reclus atribuía à montanha um lugar privilegiado para exprimir seus ideais de liberdade, solidariedade e fraternidade entre os povos. Mas além do conteúdo fortemente político de seus estudos, evidencia-se aqui uma percepção científica tão sofisticada quanto extemporânea. Na realidade, Reclus tematizava algo que estudos muito recentes vieram a explorar: a incapacidade da matemática clássica, absolutamente predominante no século XIX, de explicar satisfatoriamente as formas geométricas da natureza. A obra de Reclus data da década de 1880, alguns anos antes de o matemático francês Henri Poincaré (1854-1912) entrever a possibilidade de caos nos sistemas de determinação e sistematizar as bases da matemática topológica que, no século XX, seria apropriada na elaboração da teoria do Caos. Poincaré foi uma voz isolada e ignorada em seu tempo, quando os procedimentos lógicos linearizavam o não-linear na obsessão de reduzir todos os fenômenos a equações numéricas, creditando aos números a explicação de tudo.? 
Entretanto, "nuvens não são esferas, montanhas não são cones, litorais não são círculos, a casca das árvores não é lisa e tampouco a luz viaja em linha reta", 8 antes são formas fractais irredutíveis às categorias determinísticas tradicionais. Ao criticar a tentativa de submissão das formas naturais às figuras geométricas ou equações numéricas, Reclus apontava justamente a impossibilidade de os saberes matemáticos de seu tempo captarem verdadeiramente a textura da realidade. Nesse caso, ele aparece como um revolucionário também no que diz respeito à lógica científica propriamente dita.

Uma estimulante riqueza de aspectos emergia da região geográfica do Etna, com paisagens de bosques de carvalhos e pinhos, mas também "corredores de neve, escarpas de cinzas e rastros de resíduos vulcânicos”, assim como pastos e campos cultivados pelos numerosos habitantes que ali construíam suas vidas e seu futuro, em um solo incrivelmente fertilizado pela própria atividade vulcânica e por cursos de água. Reclus lamentava como a ignorância e a imprevidência dos homens os levavam a devastar a vegetação local. Porém, considerou a relativa segurança de suas vidas - com exceção dos momentos de instabilidade da cratera - mais felizes do que as de tantos citadinos vitimados por esgotos pútridos ou das inúmeras populações de áreas pantanosas dizimadas pela malária. ${ }^{9}$

O interesse de Reclus pelos vulcões e montanhas certamente se inseriu num amplo fascínio pelo que ele mesmo denominaria, em obra posterior, forças telúricas, cuja ação estaria intimamente ligada à sucessão dos fatos humanos. Naquele ano da explosão do Etna, o geógrafo vivia momentos decisivos em sua vida, marcados pela definitiva aproximação com o anarquismo. Nascido em 1830 numa pequena cidade francesa, Sainte-Foy-la-Grande, filho de um pastor calvinista, Reclus foi criado pelo pai para seguir a mesma carreira. Ainda adolescente, entretanto, foi expulso de um curso de teologia protestante ao defender idéias republicanas. Havia se iniciado nos estudos de geografia em Berlim, quando voltou às pressas para a França, envolvendo-se nas lutas políticas que precederam o golpe de 1851. Reclus participou de um episódio em Ortez, no qual vários jovens tentaram impedir o apoio da guarda local ao Imperador. Após a vitória de Luís Napoleão, exilou-se e dedicou-se a um período de experiências e viagens pela Inglaterra, Estados Unidos e alguns países da América Latina, realizando anotações de caráter geográfico. Em 1857, voltou à França, onde seus escritos alcançaram grande êxito. Em 1862, foi convidado a ingressar na Sociedade Geográfica de Paris. ${ }^{10}$

No decorrer de suas viagens, Reclus teve suas convicções protestantes e mesmo republicanas abaladas. Ao retornar, aproximou-se dos meios socialis- 
tas, passando a ter contato com inúmeros militantes de movimentos rebeldes. Em 1864, conheceu Mikhail Bakunin. O líder russo, atuante nos movimentos de 1848, em Paris, e de 1849, em Dresden, havia sido preso e enviado para a Fortaleza de Pedro e Paulo, na Rússia. Sua resistência tornara-se um símbolo para toda uma geração de rebeldes, como relatou Kropotkin que, preso anos depois na mesma instituição, consolava-se com o pensamento de que Bakunin saíra dali "mais disposto e mais forte do que seus camaradas que continuavam em liberdade". Bakunin reiniciou com vigor suas atividades, retornando à Europa, envolvendo-se nas insurreições de povos eslavos e perambulando por vários países, sempre se associando aos movimentos revolucionários locais. Suas concepções radicais afirmavam a contestação como uma necessidade humana, em que os gestos destruidores revestiam-se de um valor intrínseco. Seus ideais eram povoados de imagens avassaladoras: sonhava com "toda a Europa, incluindo São Petersburgo, Paris e Londres, transformada num imenso monte de escombros", cuja reconstrução possibilitaria o predomínio das forças criativas de uma sociedade renovada e anárquica. ${ }^{11}$

Certamente Reclus possuía contatos anteriores com as concepções libertárias, mas aqueles anos caracterizaram um período de amadurecimento na militância do geógrafo. ${ }^{12}$ Ele e seu irmão Elie entraram para a sociedade secreta "Fraternidade Internacional", fundada pelo próprio Bakunin, que considerava os dois amigos como "dois sábios, e ao mesmo tempo os homens mais modestos, os mais nobres, os mais desinteressados, os mais puros e os mais religiosamente devotados aos seus princípios" que ele encontrara em sua vida. ${ }^{13}$

Elisée Reclus, por sua vez, impressionou-se profundamente com o vigor revolucionário do novo amigo. Curiosamente, um ano após conhecê-lo, dedicou alguns importantes artigos ao estudo dos vulcões e terremotos. A marca da paixão destruidora, característica da prática libertária de Bakunin, encontra-se visível nesses escritos. As forças telúricas que tanto fascinaram o geógrafo produziam exatamente as cenas de destruição e renovação tão sonhadas pelo agitador russo, para quem "o desejo de destruir" era, sobretudo, "um desejo criativo"." ${ }^{14}$

Ao longo das décadas seguintes, Reclus defendeu a necessidade de um evento realmente extraordinário para a alteração verdadeira da ordem das coisas e a construção de uma outra sociedade. Segundo ele, os homens de seu tempo viviam no interior de um vulcão, um inferno tenebroso, no qual seria melhor se deixar morrer caso não se acalentasse a esperança da revolução. Animados por uma "força criadora", os rebeldes encontravam-se em um momento decisivo da luta contra os detentores da "força adquirida por gerações". ${ }^{15}$ 
Na sociedade estabelecida, Reclus identificava uma situação de aparente acomodamento, uma estagnação em que os homens encontravam-se verdadeiramente rodeados pela morte. Esta fazia-se presente, em primeiro lugar, na religiosidade vigente. A Igreja conquistara os medrosos e fatigados, levando-os a abdicarem da busca da felicidade e a resignarem-se em troca das promessas de salvação e redenção futura. Apregoando a caridade, a humildade e a pobreza aos "bem-aventurados", o cristianismo seguia como "uma religião dos mortos, não mais uma religião dos vivos”. A morte caracterizava ainda uma sociedade burguesa escravizada à onipotência do dinheiro, afinal "toda obediência é uma abdicação, toda sujeição é uma morte antecipada”. No avanço da militarização das nações, o recrutamento privava os homens da livre expressão, aproximando-os do crime e do insulto. Enfim, a aparente estabilidade da sociedade burguesa, contra a qual o geógrafo se opunha, fundava-se sobre "a dominação indiscutível de uns e a servidão sem esperança de outros". Tal apaziguamento, com a valorização do patriotismo e da ordem social, era antes a paz "do túmulo". ${ }^{16}$

O sucesso de uma sociedade fundada sobre a injustiça fazia-se às expensas da vida humana. A média de vida dos operários de toda a Europa girava em torno de trinta anos: morriam justamente no momento em que sua existência deveria alcançar maior intensidade. Os progressos tecnológicos serviam a poucos: enquanto milhares de crianças sucumbiam à fome e à miséria, sofisticadas incubadoras para bebês prematuros eram exibidas em exposições internacionais. Ao mesmo tempo em que a fome ceifava as vidas dos miseráveis, um absurdo desperdício presidia o estoque, transporte e comércio de gêneros alimentícios, numa lógica na qual predominavam a sede de lucro, a ganância e a especulação. ${ }^{17}$

Reclus criticou frontalmente as justificativas malthusianas para a fome de seu tempo. ${ }^{18}$ Julgou-as como parte da estratégia de dominação burguesa. Frente à evidente injustiça da sociedade — na qual coexistiam "a turba dos pobres famintos" e "alguns privilegiados satisfazendo seus apetites e vestindo-se imaginativamente" — o malthusianismo buscava legitimar a miséria existente como um fato inexorável. A causa da situação lamentável em que vivia a maior parte da população deixava de ser social para ser apresentada como uma causa natural, explicável matematicamente. E nessa naturalização do sistema vigente social, Reclus apontava desdobramentos aviltantes, nos quais a vida encontrava-se várias vezes diminuída. As altas taxas de mortalidade, decorrentes de uma lógica econômica perversa, condenavam à morte as populações famintas e privadas das condições básicas de higiene e saúde. 
No âmbito dessas existências abreviadas, propugnavam-se medidas que correspondiam ao sacrifício de uma parte da felicidade: que os pobres se abstivessem do sexo e diminuíssem sua prole.

Assim, milhões de seres humanos eram condenados à fome, às doenças, à mortalidade precoce, ao trabalho exaustivo, ao sacrifício da liberdade de pensamento, à renúncia da felicidade presente em função da promessa de um paraíso futuro e à "reserva moral" de controle da natalidade. ${ }^{19}$ Restava, aos explorados, uma vida curta e infeliz, numa ordem social apresentada como inevitável e imutável.

Contrapondo-se a tudo isso, o geógrafo Reclus ressaltava o caráter de abundância existente na riqueza da Terra, "vasta o bastante para nos abrigar em seu seio", assim como "rica o bastante para fazer-nos viver com bem-estar". A fome não era apenas o resultado de um crime coletivo, mas principalmente um absurdo decorrente da má distribuição das riquezas, da destruição imprevidente e ignorante da natureza, do desperdício e da especulação. Se os homens do passado tinham vivido sem conhecimentos e tecnologia para uma produção suficiente, vivia-se agora numa "sociedade de riquezas superabundantes", mas que um sistema de dominação controlava em proveito de poucos. ${ }^{20}$

Reclus insistiu na imagem de uma "Terre bienfaisante" não apenas em textos de explícita militância libertária - como é o caso de L'évolution, la révolution et l'idéal anarchique - mas também em seus trabalhos científicos como geógrafo. E aqui se evidencia uma característica essencial de sua obra e de seu pensamento, que é a constituição de um vigoroso padrão ético, ao longo de uma argumentação urdida nos fios da tensão entre a vida e a morte. Para Reclus, a luta contra a situação vigente afigurava-se como uma luta contra a morte. O mundo mudara, mas assim como algumas evoluções tendiam para o desenvolvimento da vida, outras se direcionavam para a morte: este último era o caso da trajetória da sociedade burguesa, mostrando como os movimentos históricos possuíam duas faces, desencadeando "evoluções chamadas 'decadência' e revoluções que são a morte". ${ }^{21}$ Ao considerar a história e as transformações sociais ao longo do tempo, Reclus baseava sua análise na afirmação ou não da vida e da felicidade humana, que emergiam como parâmetro ético fundamental de seu pensamento.

Para o geógrafo, ao reivindicarem o pão, os homens exigiam a sobrevivência, mas também as condições materiais mínimas que lhes permitiriam possuir força e saúde físicas para alcançar a alegria. A luta em curso era, sobretudo, uma batalha pela vida no seu sentido mais amplo, com tudo o que ela podia conter de afirmativo, como a solidariedade, a felicidade, o acesso ao 
conhecimento, a liberdade, o gozo dos benefícios de uma Terra generosa em suas possibilidades. Na adoção desse padrão ético, Reclus podia relativizar, por exemplo, a suposta superioridade evolutiva dos colonizadores civilizados em relação aos índios botocudos, habitantes nativos das matas do Brasil, país visitado pelo geógrafo em 1893. Tais povos se organizavam primitivamente em grupos nômades, vivendo da coleta e da caça, mergulhados em superstições, submetidos às intempéries, ignorantes das artes mais simples do artesanato e da agricultura. Entretanto, por pouco adiantados que fossem, "tinham ao menos sobre os invasores brancos a vantagem de serem livres e de viverem felizes nas suas matas".22

A sociedade burguesa aparece como frontalmente oposta à vida humana, com seus reis, sua fé e suas leis, mortos-vivos "duros de morrer", fantasmas "que deveriam ser assassinados!”. ${ }^{23}$ Para inaugurar novas formas de organização social, era preciso destruir a que existia. E aqui retornamos às imagens dos fenômenos telúricos, tão presentes no pensamento de Reclus, que evidenciavam como a evolução do planeta não se fazia sem grandes eventos de ruptura.

Em 1880, o geógrafo publicou o livro Histoire d'une Montagne, numa coleção dedicada à divulgação científica. Essa obra traz a narrativa de uma experiência pessoal, na qual o autor se refugiou numa montanha em um período de grande tristeza e desânimo. Os anos anteriores realmente haviam sido difíceis. Após as grandes esperanças e o entusiasmo vividos durantes os dias da Comuna de Paris, entre março e maio de 1871, os rebeldes haviam conhecido o amargo gosto da derrota. Mas o que mais impressionara Reclus não fora a rigidez da repressão burguesa. Antes, sua grande decepção advinha do comportamento das massas populares. Nos dias tumultuados da Comuna, "éramos seguidos de saudações tocantes, lágrimas de admiração brilhavam nos olhos dos que nos aclamavam, as mulheres agitavam seus lenços com ternura”. Logo após a derrota, os communards poupados do massacre e feitos prisioneiros haviam sido acolhidos, pelos mesmos manifestantes, com palavras de ódio e pedidos de vingança: "À morte ! À morte! À metralhadora! Ao moinho de café! À guilhotina!”. ${ }^{24}$ Reclus foi preso e submetido a julgamento, condenado ao degredo perpétuo na colônia francesa de Nova Caledônia. Um movimento internacional a seu favor conseguiu do governo francês a comutação da pena para a de exílio por dez anos. Reclus estabeleceu-se em Lugano, na Suíça, cidade à beira do lago de mesmo nome e situada entre as montanhas San Salvatore e Brè.

Alguns anos mais tarde, Reclus afirmaria a necessidade de uma larga conscientização das massas populares — sem a qual qualquer revolução esta- 
ria submetida ao sabor das "terríveis ressacas da vaga humana" — defendendo a importância de uma prática anarquista ligada à transformação das concepções e dos ideais da maior parte da sociedade. Em sua opinião, não bastava levantar barricadas, ou repetir palavras de ordem como bandeiras ao vento. Nenhuma revolução podia fazer-se sem uma evolução prévia, e os libertários desejavam muito mais que "sublevar os descontentes e precipitá-los na contenda, sem objetivo nem bússola". ${ }^{25}$ Assim, ele reconsideraria o fracasso de 1871 como um erro de estratégia da preparação revolucionária, o qual poderia ser evitado nos próximos movimentos.

Mas logo após a derrota, predominava unicamente o sentimento de decepção. Além disso, os caminhos das organizações revolucionárias apresentaram-se tortuosos, com o acirramento das controvérsias na Conferência Internacional da Association International des Travailleurs - AIT, em setembro de 1871, em Londres, com o enrijecimento e centralização da organização do movimento operário sob uma burocracia, culminando na expulsão de Bakunin e James Guillaume da AIT, em 1872, e na transferência da sede para Nova York como estratégia de enfraquecimento dos protestos libertários sobre os rumos autoritários da organização. Em julho de 1876 Bakunin morreu, o que certamente significou uma perda dolorosa para Reclus. Talvez seja a esses reveses que o geógrafo se referia quando, no primeiro parágrafo de seu livrinho, narra como se encontrava triste, abatido, cansado da vida, maltratado pelo destino, com a perda de entes queridos, a frustração de seus projetos e o aniquilamento de suas esperanças. Homens aos quais chamara de amigos o haviam traído e toda a humanidade lhe causava horror. Queria morrer e, fugindo da ruidosa cidade, refugiou-se em uma montanha, onde esperava encontrar a solidão e a quietude absolutas. ${ }^{26}$

Felizmente, a estadia na montanha revigorou-o por completo. Ali, Reclus vislumbrou a rica irregularidade das formas de seus cumes e vales; a movimentação incessante das mudanças climáticas, assim como as diferenças em relação à altitude; a mudança constante do solo pela ação dos ventos, das chuvas, dos cursos d'água; a exuberância dos bosques, assim como dos pastos e campos cultivados pelos camponeses locais; a diversidade da fauna e da flora; o fascínio das inúmeras lendas e mitos criados pelos homens em torno das montanhas. Toda a região geográfica pulsava em criação constante.

Mais que todos esses fatores, a montanha evidenciava uma dimensão temporal, em cuja imensidão talvez Reclus tenha conseguido relativizar os fatos desagradáveis de um período de sua vida dentro do contexto mais amplo da história do homem e da Terra. Tratava-se de uma longa duração, visível na 
disposição dos fósseis encontrados nas várias camadas geológicas, na lentidão em que se esculpiam os precipícios e os desfiladeiros, numa história imemorial, na qual o tempo se revelava um agente soberano, presidindo uma sucessão de fenômenos de crescimento e diminuição, num devir de destruições incessantes e renovação interminável. E tal renovação permitiu a Reclus voltar à sua vida, ao "grande tumulto dos humanos".

Dentro de uma dimensão maior de tempo é que Reclus passaria também a pensar suas atividades revolucionárias. Um ano após perder o amigo Bakunin, o geógrafo conheceu Kropotkin, que retornara à Europa ocidental como exilado político, aproximando-se dos revolucionários da Federação Jurassiana, organização fundada em 1871 por anarquistas dissidentes da AIT. Nas discussões em curso, o anarco-comunismo, ou comunismo libertário, tomou vigor entre militantes como James Guillaume, François Dumartheray, Kropotkin e o próprio Reclus.

Entre Kropotkin e Reclus surgiu uma relação de amizade e forte afinidade intelectual. Os dois eram geógrafos e alinhavam-se a uma nova concepção libertária que delineava novas estratégias revolucionárias e abandonava o coletivismo anteriormente predominante. Mas especialmente a crença no conhecimento como principal arma na luta contra a sociedade burguesa e na conscientização das multidões e seu conseqüente amadurecimento para a próxima revolução a ser empreendida surgia como pedra fundamental na prática libertária dos dois anarquistas. Era preciso conhecer e partilhar tal saber entre o maior número possível de pessoas. Era importante que todos conhecessem a história e soubessem dos avanços e limites das lutas passadas. Era essencial difundir o entendimento maior da trajetória humana na Terra, possibilitado pelo estudo científico.

Tudo isso configurava uma nova estratégia revolucionária solidificada naqueles anos, quando ressurgiram grandes esperanças. Em 1880 - mesmo ano em que Reclus publicou Histoire d'une Montagne e assinalava seu retorno à vida e ao tumulto dos homens, completamente renovado da amargura que anteriormente o abatera - a Federação Jurassiana, reunida em congresso em Chaux-de-Fonds, declarava-se "ousadamente comunista anarquista", inaugurando uma época de adesão de novos partidários por toda a França e especialmente, segundo Kropotkin, em Lyon. ${ }^{27}$ Numa nova fase de otimismo revolucionário, Reclus afirmava o fim do período do puro instinto. As revoluções já não se fariam mais ao acaso, mas seriam atos conscientes e refletidos. Assim como as erupções vulcânicas e os terremotos eram o clímax de uma lenta e imperceptível evolução em curso numa longa duração, a revolução anar- 
quista seria o ápice de uma decisiva transformação histórica nas sociedades humanas.

O conhecimento era o grande diferencial evolutivo, e para a construção de um mundo libertário tornava-se importante "prever, calcular as peripécias da luta, preparar cientificamente a vitória que nos dará a paz social”, pois “a condição primeira do triunfo é estar desembaraçado de nossa ignorância: é necessário conhecer todos os preconceitos a serem destruídos, todos os elementos hostis a serem descartados, todos os obstáculos a serem ultrapassados". O conhecimento da evolução histórica permitiria avaliar os recursos e os aliados possíveis no momento da grande explosão social. ${ }^{28}$

Contrário à visão das linhas retas, das meras continuidades, da inércia como lógica do mundo e da sociedade, Reclus seguia uma fase vigorosa de sua militância anarquista e da produção de trabalhos científicos. Entre 1875 e 1892 escreveu dezenove volumes da Nouvelle Geographie Universelle. Em 1897, publicou seu único livro de teoria anarquista, traduzido por militantes de inúmeros países, incluindo o Brasil. Nessa obra, sistematizou uma visão verdadeiramente vulcânica da revolução libertária. A nova sociedade não poderia surgir da República, nem de uma evolução em continuidade com as formas políticas existentes. Ela certamente seria o fruto de uma evolução em curso há longo tempo, mas um salto se fazia necessário, uma ruptura que configuraria uma criação.

A vida surge novamente como parâmetro essencial de Reclus. Ao contrário dos cientistas que repetiam "a natureza não dá saltos" (entre os quais Charles Darwin), para o geógrafo anarquista a vida não se mostrava em nenhuma parte como uma continuidade direta, "mas sempre uma sucessão indireta, revolucionária”. Numa árvore, um ramo não era o mero prolongamento de outro. A flor não era o mero prolongamento da folha, nem o pistilo, do estame. Os filhos não eram meros prolongamentos dos pais, mas seres novos e absolutamente distintos. Nesse ponto - assim como no que diz respeito à luta entre espécimes - o evolucionismo de Reclus diferenciava-se das teorias darwinistas e mesmo social-darwinistas, pois assumia uma perspectiva não linear. ${ }^{29}$

Aqui se delineia uma surpreendente concepção filosófica desse geógrafo. Como mostra Cornelius Castoriadis, vinte e seis séculos de tradição filosófica ocidental reafirmaram a criação como o surgimento de algo a partir de sistemas determinados, assim como a manutenção das mesmas determinações ao longo de toda a história, numa repetida explicação do que surge sendo gerado pelo que já existia antes, configurando assim o pressuposto de que nada 
poderia ser completamente novo. Para Platão, a criação era, verdadeiramente, a imitação de um modelo preexistente. Para Aristóteles, também a criação consistia em cópia. Para Kant, a imaginação efetivamente não criava nada, mas o que era produzido o era a partir de algo preexistente. Assim, a criação ocorreria no seio de um sistema de causalidades prévio que determinaria o seu alcance. ${ }^{30}$ Vimos como Reclus suspeitou dos sistemas de determinação oferecidos pela matemática clássica de sua época, obcecada em traduzir e enquadrar a realidade em equações. Somado a isso, o geógrafo também questionou os esquemas filosóficos de causalidade no que diz respeito à criação. É claro que ele considerava as condições históricas da emergência de novas formas, mas inovava ao afirmar que o novo poderia diferir radicalmente do que já existia, romper radicalmente com o que era dado, o que lhe possibilitava pensar na criação de uma sociedade radicalmente inovadora.

É no surgimento do novo, através de uma diferenciação radical característica da vida, que Reclus identifica o momento revolucionário. Parâmetro ético presente em toda a sua obra, a vida também era o elemento que fundamentava a revolução anarquista. No grande salto a ser feito, na explosão vulcânica da ação de novos homens, completar-se-ia o movimento de uma longa evolução, configurando uma revolução e a vitória dos ideais anarquistas de uma nova vida e da criação de uma sociedade diversa, na expectativa de grandes dias, acalentada por grandes esperanças.

\section{NOTAS}

${ }^{1}$ Uma versão resumida deste trabalho foi apresentada em mesa redonda no Colloque International Elisée Reclus et nos géographies, textes et prétextes, Lyon, setembro de 2005, por ocasião do centenário da morte do geógrafo anarquista. Apoio CNPq.

${ }^{2}$ RECLUS, Elisée. Le mont Etna et l'eruptión de 1865. Revue des Deux Mondes, Paris, v.LVIII, p.110-38, 1865.

${ }^{3}$ RECLUS, E. Le mont Etna..., p.117.

${ }^{4}$ RECLUS, Elisée. Les oscillations du sol terrestre. Revue des Deux Mondes, Paris, v.LV, p.5784, 1865; RECLUS, Le mont Etna..., p.127.

${ }^{5}$ PELLETIER, Phillipe. John Clark analysant Pelletier, Philippe. John Clark analysant Elisée Reclus, ou comment prendre ses desirs pour des realités. Le Monde Libertaire, Paris, n.1065, 1997; PELLETIER, Philippe. L'enjeu intellectuel et politique d'Elisée Reclus, réponse à John P. Clark. Le monde libertaire, Paris, n.1085, 1997; CLARK, John. Du bon usa- 
ge d'Elisée Reclus. Le Monde Libertaire, Paris, n.1079, 1997. Disponível em www.federation-anarchiste.org/, acesso em 21.07.2005.

${ }^{6}$ RECLUS, Elisée. Evolução, revolução e ideal anarquista. (1897). São Paulo: Imaginário, 2002. p.49, 109; RECLUS, Elisée. La montaña. (1880). Buenos Aires: Nueva Biblioteca Filosofica Tor, s.d. p.11.

${ }^{7}$ STEWART, Ian. Será que Deus joga dados? A nova matemática do caos. Rio de Janeiro: Jorge Zahar, 1991. p.64, 92-5, 232-40; GLEICK, James. Caos, a criação de uma nova ciência. Rio de Janeiro: Campus, 1990. p.208-33; POLITIS-STERGIOU, Evangelos. La contribution d'Elisée Reclus à la construction de l'object scientifique de la montagne pour une géographie humaniste. In: COLLOQUE ELISÉE RECLUS ET NOS GÉOGRAPHIES, 1, 2005, Résumé. Lyon: Université Lyon 2. p.3.

${ }^{8}$ MANDELBROT, Benoit B. The fractal geometry of nature. New York: W. H. Freeman and Company, 1977. p.1.

${ }^{9}$ RECLUS, E. Le mont Etna..., p.120-2, 134, 136-7.

${ }^{10}$ GIBLIN, Beatrice. Elisée Reclus: un géographe d'exception. Herodote, Paris, n.117, p.13, 1981; RECLUS, Elisée. L’Homme et la Terre. Paris: Librairie Universelle, 1905. v.1, p.II.

${ }^{11}$ BAKUNIN, M. citado por WILSON, Edmund. Rumo à Estação Finlândia. São Paulo: Companhia das Letras, 1986. p.256; KROPOTKIN, P. Em torno de uma vida, memórias de um revolucionário (1899). Rio de Janeiro: J. Olympio, 1946. p.326.

${ }^{12}$ GIBLIN, Béatrice. Elisée Reclus, 1830-1905. Herodote, Paris, n.2, 2005. Disponível em www.herodote.org/article.php3?id_article=149; DUARTE, Regina Horta. Elisée Reclus, geografia e anarquismo - visões da revolução. LPH: Revista de História, Ouro Preto, v.3, n.1, p.80-94; PELLETIER, P. Elisée Reclus: géographe ou écologue? anarchiste ou écologiste? Itinéraire, Paris, n.14, p.29-39, 1998.

${ }^{13}$ BAKUNIN, M. (1871) citado por NETLAU, Max. Correspondance de Elisée Reclus. Tome deuxième, oct. 1870-juil. 1899. Paris: Librairie Schleicher Frères, 1911.p.166.

${ }^{14}$ WILSON, E. Rumo à Estação Finlândia..., p.256; RECLUS, E. Les oscillations du sol...; RECLUS, Le mont Etna...; RECLUS, La Sicille et l'eruptión de l'Etna en 1865: récit de voyage. Le Tour du Monde, Paris, v.13, p.353-416.

${ }^{15}$ RECLUS, E. Evolução, revolução e ideal anarquista..., p.48-54.

${ }^{16}$ RECLUS, E. Evolução, revolução e ideal anarquista..., p.54, 61, 65, 103.

${ }^{17}$ Ibidem, p.71-3.

${ }^{18}$ PELLETIER, P. Elisée Reclus: géographe ou écologue ?..., p.29-39.

${ }^{19}$ RECLUS, Evolução, revolução e ideal anarquista..., p.70-1.

${ }^{20}$ Ibidem, p.68.

${ }^{21}$ Ibidem, p.29; RECLUS, E. Nouvelle Géographie Universelle. 19v. Paris: Hachette, 1876- 
1894; RECLUS, Estados Unidos do Brasil - geographia, ethnographia, estatística (1893). Rio de Janeiro/Paris: Garnier, 1900; RECLUS, L'Homme et la Terre. 6v. Paris: Librairie Universelle, 1905.

${ }^{22}$ RECLUS, Evolução, revolução e ideal anarquista..., p.212; ANDRADE, Manuel Correia de. Elisée Reclus, geografia. São Paulo: Ática, 1985. p.14.

${ }^{23}$ RECLUS, Evolução, revolução e ideal anarquista..., p.114.

${ }^{24}$ Ibidem, p.39. Segundo o tradutor Plínio Augusto Coelho, "moinho de café" era o apelido dado, na época, à metralhadora.

${ }^{25}$ Ibidem, p.31.

${ }^{26}$ RECLUS, E. La montana..., p.5; LUIZETTO, Flávio. Presença do anarquismo no Brasil: um estudo dos episódios literário e educacional, 1900-1920. São Paulo, 1984. Tese (Doutorado em História) — FFLCH, USP. p.20-33.

${ }^{27}$ KROPOTKIN, P. Em torno de uma vida..., p.420.

${ }^{28}$ RECLUS, E. Evolução, revolução e ideal anarquista..., p.51.

${ }^{29}$ Ibidem, p.26-7; LACOSTE, Yves. Elisée Reclus: une très large conception de la géographicité et une bienveillante géopolotique. Herodote, Paris, n.117, 2005. Disponível em www.herodote.org/article.php3?id_article $=149$.

${ }^{30}$ CASTORIADIS, Cornelius. A instituição imaginária da sociedade. Rio de Janeiro: Paz e Terra, 1982. p.231-9; CASTORIADIS, As encruzilhadas do labirinto, 3: O mundo fragmentado. Rio de Janeiro: Paz e Terra, 1992. p.261-93. 